\title{
Morbidity in Patients Undergoing Hypogastric Artery Ligation at Risk of Obstetric Bleeding
}

\author{
Angel Saucedo López ${ }^{1 *}$, Manuel Gea González², Angel García Briones ${ }^{3}$, Armando Velázquez Merino ${ }^{4}$, Ernesto \\ Corona Alvarado ${ }^{4}$ and Alejandra Gómez Fernández ${ }^{5}$ \\ ${ }^{1}$ High Specialty in Infertility and Assisted Reproduction, Valencian Institute of Infertility, Gynecological Endoscopic Surgery, General Hospital of Mexico, \\ Mexico \\ ${ }^{2}$ Gineco-Obstetra Physician Attached to the Hospital Gineco-Pediatría 3rd Mexican Institute of Social Security, Mexico \\ ${ }^{3}$ Doctor of Gynecology - oncologist of the Regional General Hospital No. 36 San Alejandro Puebla, Mexican Institute of Social Security, Mexico \\ ${ }^{4}$ Critical Medicine and Intensive Therapy. Intensive Care Unit of the Regional General Hospital No. 36 San Alejandro Puebla, Mexican Institute of Social \\ Security, Mexico \\ ${ }^{5}$ Gineco-Obstetra Attached to the Hospital Gineco-Pediatría 3A, Mexico
}

Submission: November 03, 2020; Published: November 10, 2020

*Corresponding author: Angel Saucedo López, High Specialty in Infertility and Assisted Reproduction, Valencian Institute of Infertility (Mexico), Gynecological Endoscopic Surgery, General Hospital of Mexico, Mexico

\section{Summary}

Background: Obstetric bleeding is the leading cause of maternal mortality underdeveloped countries, account for one-third of deaths. Alternative surgical techniques are available to stop bleeding such as ligation of hypogastric arteries.

Objective: To determine maternal morbidity in patients undergoing hypogastric artery ligation at risk of obstetric bleeding from June to December 2012 in H.G.R. 36 I.M.S.S Puebla.

Material and Methods: Descriptive, observational, transversal, ambilective, homodemic study. Patients at risk of obstetric bleeding under "hypogastric artery ligation" were included from June to December 2012 at H.G.R. 36 I.M.S.S. Puebla, of any maternal and gestational age. The Tipo and sample size was finite, not probabilistic. Statistical method: descriptive and Odds.

Results: 38 patients underwent hypogastric artery ligation. Average age: 26.9 years. Placentalacretism (44.74\%) was the most common indication Odds 0.78 , followed by uterine hypotonia (7.89\%) Odds -0.07 and placenta previa $(7.89 \%)$ Odds x 0.07 . There were $22(57.8 \%)$ patients with obstetric bleeding, 15 (68.18\%) had previous C-section background Odds Odds 2.12 . The probability of culminating in Odds obstetric hemorrhage hysterectomy is 4.2. Se documented 1 (2.63\%) patient with post-ligature ureteral complication Odds 0.027 . Maternal and perinatal mortality of $0 \%$.

Conclusion: Complication after ligation of hypogastric arteries was presented in 1 patient with ureteral ligation. There were no vascular complications. Maternal mortality was $0 \%$. Perinatal mortality was $0 \%$.

Keywords: Hypogastric artery ligation; Obstetric bleeding; Maternal morbidity; Maternal mortality; Vascular complications; Perinatal mortality

\section{Background}

Postpartum bleeding remains the leading cause of death in under developed countries, which account for about one-third of maternal deaths in Latin America, Asia and Africa [1-3]. An estimated blood loss of more than $500 \mathrm{ml}$ after vaginal delivery or a loss of more than $1,000 \mathrm{ml}$ cesarean birth has often been used for the diagnosis of obstetric bleeding [4,5]. In Mexico, it is estimated that $86 \%$ of deaths occur in hospital units. Patients who had vaginal births had a slightly higher prevalence of postpartum bleeding than those who had cesarean deliveries [2,6-24]. In 2010, only 115 women died in the State of Mexico per 100,000 inhabitants, while in 2009 that figure was 166 cases [17,20,22].

Bleeding is the leading cause of death secondary to hypovolemic shock, before this occurs, early onset of coagulopathy has been shown. Hypothermia, acidosis, and dilution resulting 
from common resuscitation actions can worsen coagulopathy $[13,19,22]$. The latter can be complicated by hypothermia and acidosis, both leading to defective clotting $[7,12,14]$.

Callagan (2010 AJOG) concluded that cesarean delivery without induction of labor has higher rates of postpartum bleeding $[5,8,10]$. The American College of Gynecology and Obstetrics reports that the risk factors for postpartum hemorrhage are: Prolonged Labor, Precipitated Labor, Postpartum Hemorrhage History, Medium Lateral Episiotomy, Preeclampsia, Uterine Overdistension (macromic products, multiple pregnancy, polyhydramnios), Ethnic Asian and Hispanic, Corioamnioitis, Cesarean delivery $[6,9,11,16,18,19]$. In cases of postpartum hemorrhage, first-line treatment includes uterotonic agents with or without procedures intended for uterine capping. If the latter fails, the following treatment focuses on surgical procedures such as ligation of uterine/hypogastric arteries or hysterectomy, rescue surgeries associated with saving the patient's life [22].

Hypogastric artery ligation (H LAH) is a surgical technique by which internal (hypogastric) iliac arteries are ligate to its anterior branch $[21,23]$. The indications are classified into 2 types:

Profilactica and Therapeutic: Prophylactic is when performed prior to a non-obstetric pelvic surgical procedure, for the sole purpose of preventing intense bleeding during surgery [21].

Terapeutica: This is when the ligature is performed after a non-obstetric pelvic surgical procedure, in order to inhibit bleeding secondary to the same surgery [21].

Prophylactic indications of uterine artery ligation in obstetrics are: uterine atonia, placenta acreta, Couvalaire uterus. Complications of hypogastric artery ligation are classified into vascular lesions and ureteral lesions.

Vascular Injury: This group is the outer iliac artery ligation, hypogastric artery tear, hypogastric vein tear and sacral venous plexus injury [21].

Ureteral Injuries: Conditioning, wall injury, ligature, total section. Late complications are those that occur after the first 10 days of postoperative: we have buttock atrophy and bladder necrosis. Because there are no studies reporting maternal morbidity in patients undergoing hypogastric artery ligation at risk of obstetric bleeding, so interest arises to conduct this research.

\section{Material and Methods}

Descriptive, observational, transversal, ambilective, homodemic study. Patients at risk of obstetric bleeding under "hypogastric artery ligation" were included from June to December 2012 at H.G.R. 36 I.M.S.S. Puebla, of any maternal and gestational age. The Tipo and sample size was finite, not probabilistic. Statistical method: descriptive and Odds.

\section{Results}

A total of 38 postoperative women of hypogastric artery ligatures at risk of obstetric bleeding were included from June to December 2012 at the Regional General Hospital number 36 of the Mexican Institute of Social Security Puebla. The results found were analyzed below.

The average age was 26.9 , minimum of 16 years and maximum of 37 years, 5.38 years. The details are shown in Table I. The average body mass index was 28.61, minimum 21.6, maximum 35.5 and 3.47. Details are presented in Table 2. One (2.63\%) patient was found to carry uterine myomatosis and $37(97.36 \%)$ patients is not presented in Table 3. Reported to $23(60.5 \%)$ patients with prior C-section and $1(2.63 \%)$ patient with myomectomy history as seen in Table 4.

Table I: It shows the age of the patients studied (source: clinical record).

\begin{tabular}{|c|c|c|c|}
\hline \multicolumn{4}{|c|}{ Age } \\
\hline No. 38 & Average 26.9 & *oF 5.38 & \\
\hline Age & Frequency & Percentage & ODDS \\
\hline $16-20 \mathrm{a}$ & 4 & 10.53 & 0.12 \\
\hline $21-25 \mathrm{a}$ & 12 & 31.58 & 0.46 \\
\hline $26-30 \mathrm{a}$ & 10 & 26.32 & 0.36 \\
\hline $31-35 \mathrm{a}$ & 9 & 23.68 & 0.31 \\
\hline $36-40 \mathrm{a}$ & 3 & 7.89 & 0.09 \\
\hline TOTAL & 38 & 100 & \\
\hline
\end{tabular}

${ }^{*} \mathrm{DE}$ - standard deviation.

Table 2: Displays the body mass index of the patients studied (source: clinical record). ${ }^{*} \mathrm{DE}$ - standard deviation.

\begin{tabular}{|c|c|c|c|c|}
\hline \multicolumn{2}{|c|}{ IMC } \\
\hline \multicolumn{2}{|c|}{ No. } & $\begin{array}{c}\text { Average: } \\
\text { 28.6 years }\end{array}$ & \multicolumn{2}{c|}{ *OUT OF 3.47 } \\
\hline Parameter & Ranges & Frequency & Percentage & ODDS \\
\hline Normal & $18-24.99$ & 4 & 10.53 & 0.12 \\
\hline Overweight & $25-29.9$ & 20 & 52.63 & 1.11 \\
\hline Obesity I & $30-34.9$ & 12 & 31.58 & 0.46 \\
\hline Obesity Ii & $35-39.9$ & 2 & 5.26 & 0.06 \\
\hline Total & & 38 & 100 & \\
\hline
\end{tabular}

Table 3: It shows the antecedent of uterine myomatosis in the patients studied (source: clinical record). ${ }^{*} \mathrm{DE}$ - standard deviation.

\begin{tabular}{|c|c|c|c|}
\hline \multicolumn{4}{|c|}{ Myomatosis Uterine } \\
\hline No. 38 & Average 0.19 & $*$ OF 0.16 & \\
\hline Miomatosis & Frequency & $\%$ & ODDS \\
\hline This & 1 & 2.63 & 0.02 \\
\hline Absent & 37 & 97.36 & - \\
\hline TOTAL & 38 & 100 & \\
\hline
\end{tabular}


Table 4: Displays the antecedent of previous surgery in the patients studied (source: clinical record). *DE - standard deviation.

\begin{tabular}{|c|c|c|c|}
\hline \multicolumn{4}{|c|}{ Previous Surgery } \\
\hline No. & 38 DE 0.48 & & \\
\hline Previous Surgery & Frequency & $\%$ & ODDS \\
\hline No & 14 & 36.84 & 0.56 \\
\hline Cesarea & 23 & 60.53 & 1.5 \\
\hline Myomectomy & 1 & 2.63 & 0.02 \\
\hline TOTAL & 38 & 100 & \\
\hline
\end{tabular}

Table 5: Shows patients with uterine overdistension in the study (source: clinical record). ${ }^{*} \mathrm{DE}$ - standard deviation.

\begin{tabular}{|c|c|c|c|}
\hline \multicolumn{4}{|c|}{ Sobredistensión Uterina } \\
\hline No. 38 & DE 0.34 & & \\
\hline Uterine Sobredistension & Frequency & $\%$ & ODDS \\
\hline None & 33 & 86.84 & - \\
\hline Multiple Pregnancy & 3 & 7.89 & 0.08 \\
\hline Macrosomia & 2 & 5.26 & 0.05 \\
\hline TOTAL & 38 & 100 & \\
\hline
\end{tabular}

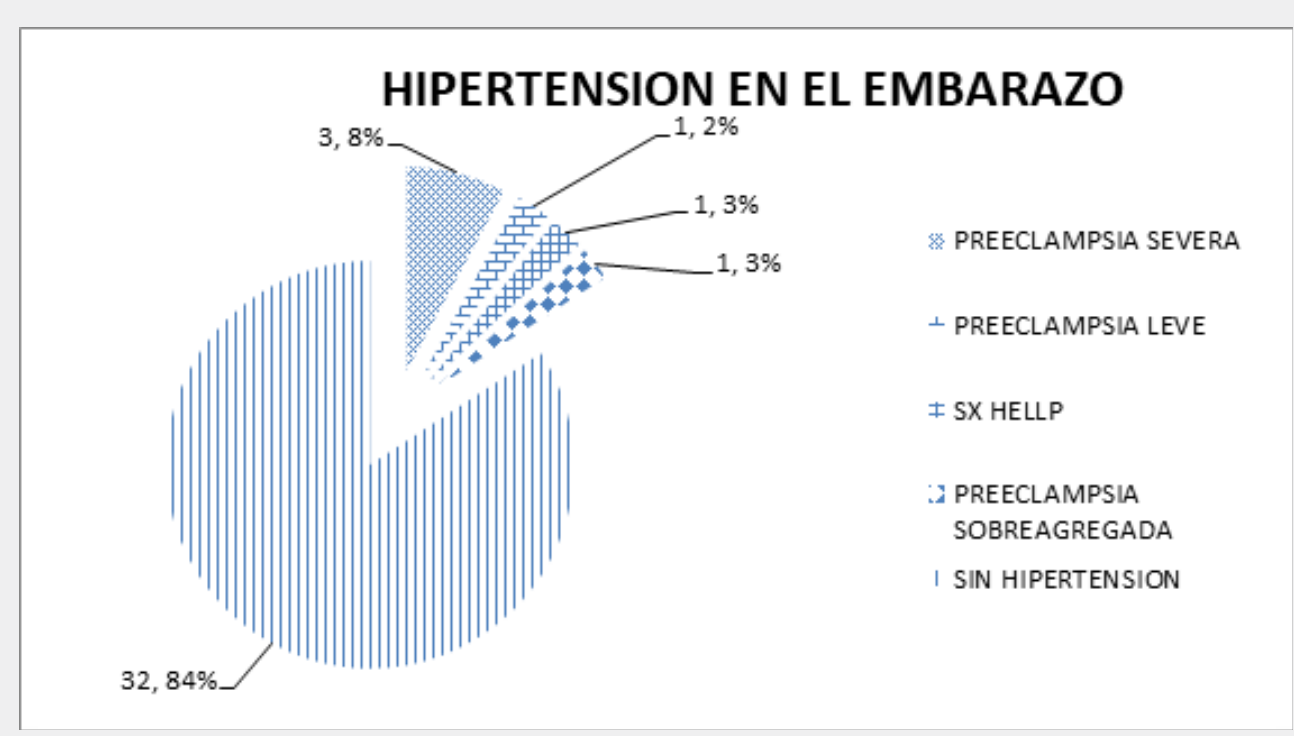

Figure 1: Shows the percentage of patients in the study who had hypertension during pregnancy.

"Hypertensive disease in pregnancy" (Figures 1 \& 2) was present in $1(2.63 \%)$ patient with mild preeclampsia; severe preeclampsia at $3(7.8 \%)$ patients; HELLP syndrome in 1 (2.63\%) patient and over-added preeclampsia by 1 (2.63\%) Patient. Found
$5(13.15 \%)$ patients with uterine overdistension, 3 (7.89\%) patients with multiple pregnancy and 2 (5.2\%) patients with Macrosomic products (Table 5).

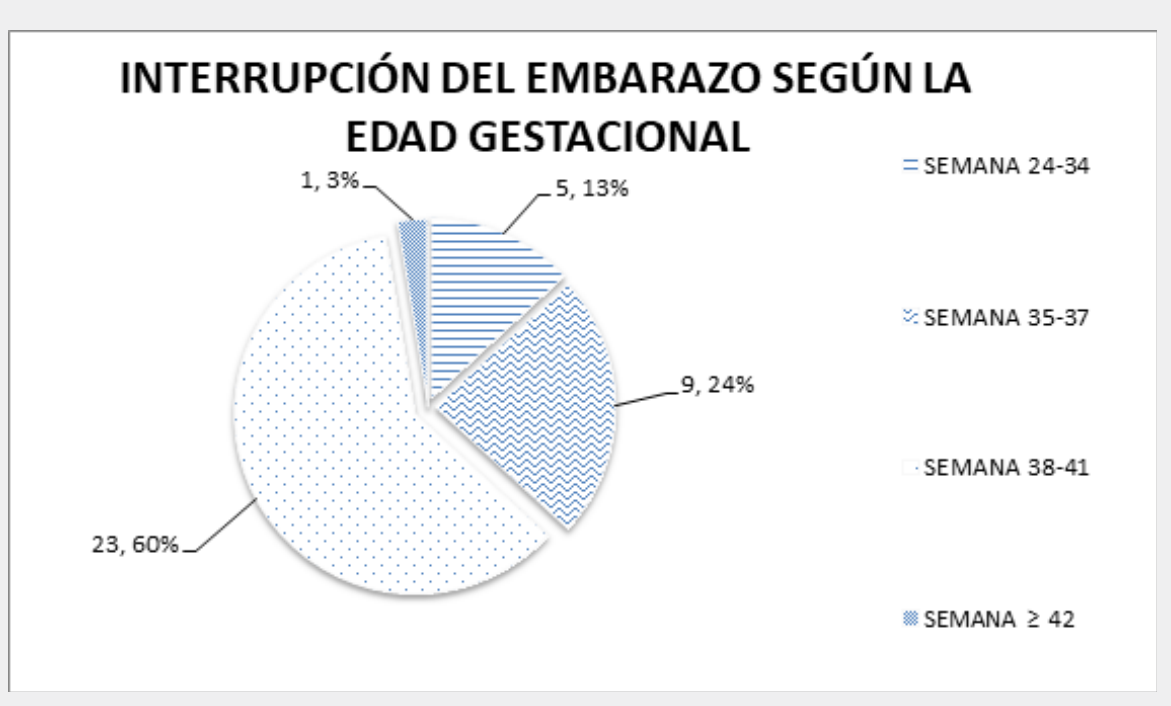

Figure 2: Shows the gestational age (percentage) of patients in the study at which they completed their gestation. 
Registered at $2(5.2 \%)$ patients with long-term labor history and $36(94.8 \%)$ patients who didn't present it. 1 (2.63\%) was identified patient with precipitous labor history dystocy (TDPP) and $2(5.2 \%)$ patients with long-term expelative disstocia (P.E.P.). The risk factor "use of uteroinhibitors" was presented 2 (5.2\%) patients with prior treatment based on magnesium sulfate and 3 (7.8\%) patients with nifidipine. 14 (36.85\%) were documented patients using "oxytocin" and $24(63.15 \%)$ patients without this (Tables 6-10). 3 (7.8\%) were found patients with induction of labor with Dinoprostone ${ }^{\circledR}$ (PGE2) and 35 (92.1\%) patients without this. "Disruption of pregnancy according to gestational age" was presented under the following conditions: 5 (13.15\%) patients between week 24 - 34; 9 (23.68\%) patients at week 35$37 ; 23(60.5 \%)$ patients at week $38-41 ; 1(2.63 \%)$ 42nd week of gestation (Tables $11 \& 12$ ). In terms of the route of termination of pregnancy, $29(76.31 \%)$ were recorded patients who completed cesarean delivery and 9 (23.68\%) patients by vaginal delivery, of which they can be broken down as follows:

Table 6: Shows patients with long-term labor history in the study (source: clinical record). ${ }^{*} T D P$ - Labor ${ }^{* *} D E$ - standard deviation.

\begin{tabular}{|c|c|c|c|}
\hline \multicolumn{3}{|c|}{ Prolonged Labor } \\
\hline \multirow{2}{*}{ No. 38 } & DE 0.34 & & \\
\hline *Prolonged TDP & Frequency & $\%$ & ODDS \\
\hline Absent & 37 & 97.3 & - \\
\hline This & 1 & 2.63 & 0.02 \\
\hline TOTAL & 38 & 100 & \\
\hline
\end{tabular}

Table 7: It shows patients with a history of dystocia in the study (source: clinical record). ${ }^{*} D E$ - standard deviation.

\begin{tabular}{|c|c|c|c|}
\hline \multicolumn{4}{|c|}{ Distocia } \\
\hline No. 38 & Average 0.07 & $*$ OF 0.27 & \\
\hline DISTOCIA & Frequency & $\%$ & ODDS \\
\hline TDPP & 1 & $2.63 \%$ & 0.02 \\
\hline P.E.P. & 2 & $5.20 \%$ & 0.05 \\
\hline SIN DISTOCIA & 35 & $92.10 \%$ & - \\
\hline TOTAL & 38 & $100 \%$ & \\
\hline
\end{tabular}

Table 8: It shows patients with a history of using uteroinhibitors in the study (source: clinical record). ${ }^{*} D E$ - standard deviation.

\begin{tabular}{|c|c|c|c|}
\hline \multicolumn{5}{|c|}{ Use of Uteroinhibitors } \\
\hline $\begin{array}{c}\text { No. 38 } \\
\text { - DE 0.34 }\end{array}$ & & & \\
\hline Uteroinhibidor & Frequency & $\%$ & ODDS \\
\hline Mg sULfate & 2 & $5.20 \%$ & 0.05 \\
\hline Nifedipino & 3 & $7.89 \%$ & 0.07 \\
\hline None & 33 & $86.84 \%$ & - \\
\hline TOTAL & 38 & $100 \%$ & \\
\hline
\end{tabular}

Table 9: Shows patients with an oxytocin employment history in the study (source: clinical record). ${ }^{*} D E$ - standard deviation.

\begin{tabular}{|c|c|c|c|}
\hline \multicolumn{4}{|c|}{ Use of Oxytocin } \\
\hline No. 38 & -DE 0.48 & & \\
\hline Treatment & Frequency & $\%$ & ODDS \\
\hline With Oxytocin & 14 & $36.85 \%$ & 0.56 \\
\hline No Oxytocin & 24 & $63.15 \%$ & - \\
\hline TOTAL & 38 & $100.00 \%$ & \\
\hline
\end{tabular}

Table 10: Shows patients with an employment history of Dinoprostone $\circledast(P G E 2)$ in the study (source: clinical record). ${ }^{*} D E$ - standard deviation.

\begin{tabular}{|c|c|c|c|}
\hline \multicolumn{4}{|c|}{ Labor Induction } \\
\hline No. 38 & -DE 0.27 & & \\
\hline Treatment & Frequency & $\%$ & ODDS \\
\hline With Dinoprostone & 3 & $7.89 \%$ & 0.08 \\
\hline No Dinoprostone & 35 & $92.11 \%$ & - \\
\hline TOTAL & 38 & $100.00 \%$ & \\
\hline
\end{tabular}

Table 11: It shows the path of resolution of pregnancy of the patients studied (source: clinical record).

\begin{tabular}{|c|c|c|c|}
\hline \multicolumn{4}{|c|}{ Pregnancy Resolution Way } \\
\hline \multicolumn{3}{|c|}{ No. 38 } \\
\hline Birth & Frequency & $\%$ & ODDS \\
\hline Vaginal & 9 & $7.89 \%$ & 0.07 \\
\hline Cesarea & 29 & $92.11 \%$ & 11.5 \\
\hline TOTAL & 38 & $100.00 \%$ & \\
\hline
\end{tabular}

Table 12: Displays the indication (absolute or relative) of the C-section of the patients studied (source: clinical record).

\begin{tabular}{|c|c|c|}
\hline \multicolumn{2}{|c|}{ C-Section Indication } \\
\hline Absolute Indication & Frequency & $\%$ \\
\hline Iterative C-section & 6 & $15.79 \%$ \\
\hline Placental acretism & 5 & $13.16 \%$ \\
\hline Placenta previa & 3 & $7.89 \%$ \\
\hline Placenta low insertion & 1 & $2.63 \%$ \\
\hline Otras (P. PELVICO, SFA, RCIU, DPPNI, & 0 & $0.00 \%$ \\
\hline etc) & & \\
\hline RELATIVE INDICATIONS & 4 & $10.53 \%$ \\
\hline EHIE & 3 & $7.89 \%$ \\
\hline multiple pregnancy & 3 & $7.89 \%$ \\
\hline dynamic dystocia & 2 & $5.26 \%$ \\
\hline DCP & 1 & $2.63 \%$ \\
\hline commitment of hysterorffia & 1 & $2.63 \%$ \\
\hline Elective C-section. & 0 & 0 \\
\hline Other (Postterm, Isomunicado, DM, \\
etc.)
\end{tabular}




\section{Journal of Gynecology and Women's Health}

In question to cesarean delivery, they were classified according to the type of indication according to the clinical practice guide of the I.M.S.S. "'for the realization of C-section operation. July 2009": Absolute to 15 (39.47\%) patients; 14 (36.84\%) patients, as shown in the following table. The presence of transoperative bleeding in postoperative patients with hypogastric artery ligation was variable, with at least $550 \mathrm{cc}$ bleeding and maximum trans surgical bleeding of $4500 \mathrm{cc}$. The details are shown in the following table (Tables 13 \&14).

Table 13: Displays the volume of transoperative bleeding of the patients studied (source: clinical record).

\begin{tabular}{|c|c|c|}
\hline \multicolumn{3}{|c|}{ Transoperative Bleeding } \\
\hline No. 38 & Average: 1485cc & $\mathbf{1 0 2 7} \mathbf{c c}$ \\
\hline Volume & Frequency & $\%$ \\
\hline 500 a 1000cc & 20 & 52.63 \\
\hline 1001 a 1500 & 4 & 10.53 \\
\hline 1501 a 2000 & 6 & 15.79 \\
\hline 2001 a 2500 & 3 & 7.89 \\
\hline 2501 the but & 5 & 13.16 \\
\hline TOTAL & 38 & 100 \\
\hline
\end{tabular}

Table 14: It shows the number of patients with obstetric hysterectomy + ligation of hypogastric arteries and patients who only had hypogastric artery ligature in the study (source: clinical record).

\begin{tabular}{|c|c|c|}
\hline \multicolumn{3}{|c|}{ Quirurgic Procedure } \\
\hline No. 38 & Frequency & Percentage \\
\hline HTA OBSTETRICA + LAH & 24 & $63.15 \%$ \\
\hline LAH & 14 & $36.84 \%$ \\
\hline TOTAL & 38 & $100 \%$ \\
\hline
\end{tabular}

Reported to 24 (63.15\%) patients who had obstetric hysterectomy + hypogastric artery ligation and 14 (36.84\%) patients who were only given the ligature. A total of 41 live birth products were recorded (there were 3 multiple "gemelar" pregnancies), there was no perinatal death, the details are shown in Table 1514 patients were documented (36.85\%) who did not warrant hemotransfusion and 24 patients $(63.15 \%)$ than if he used blood products Table 16 .

Table 15: Displays the report of newborns in the study secondary to the Hypogastric artery ligature procedure (source: clinical record). ${ }^{*} D E$ - standard deviation.

\begin{tabular}{|c|c|c|}
\hline \multicolumn{3}{|c|}{ Births } \\
\hline Sex & Frequency & $\%$ \\
\hline Male & 22 & $53.65 \%$ \\
\hline Female & 19 & $46.34 \%$ \\
\hline TOTAL & 41 & $100 \%$ \\
\hline \multicolumn{3}{|c|}{ Weight } \\
\hline Weight & AVERAGE 2856GR & $*$ OF 575 \\
\hline Minimum & 1500 & \\
\hline Maximum & 3820 & \\
\hline \multicolumn{3}{|c|}{ Size } \\
\hline
\end{tabular}

\begin{tabular}{|c|c|c|}
\hline Size & AVERAGE 48.19CM & *OF 3.26 \\
\hline Minimum & $40 \mathrm{CM}$ & \\
\hline MAXIMA & $55 \mathrm{CM}$ & \\
\hline \multicolumn{3}{|c|}{ APGAR } \\
\hline APGAR & 1 MINUTE & 5 MINUTES \\
\hline Minimum & 1 & 6 \\
\hline Maximum & 9 & 9 \\
\hline \multicolumn{3}{|c|}{ Capurro } \\
\hline \multirow[t]{2}{*}{ Weeks } & Frequency & *OF 2.72 \\
\hline & & AVERAGE 37.34 WEEKS \\
\hline 24 - 34 WEEKS & 5 & 13.16 \\
\hline 35 - 37 WEEKS & 9 & 23.68 \\
\hline 38 - 41 WEEKS & 23 & 60.53 \\
\hline$\geq 42$ WEEKS & 1 & 2.63 \\
\hline
\end{tabular}

Table 16: Displays the report of patients who warranted hemotransfusion during the Hypogastric Artery Ligature procedure (source: clinical record). ${ }^{*} D E$ - standard deviation.

\begin{tabular}{|c|c|c|}
\hline \multicolumn{3}{|c|}{ Hemotransfusión } \\
\hline No. & 38 DE 0.48 & \\
\hline Treatment & Frequency & Percentage \\
\hline No Hemotransfusion & 14 & $36.85 \%$ \\
\hline With Hemotransfusion & 24 & $63.15 \%$ \\
\hline TOTAL & 38 & $100.00 \%$ \\
\hline
\end{tabular}

During the transoperative period there was an average hemotransfusion of 1.12 "globular packages", 0.99 bag of "fresh frozen plasma" and 1.14 bag of "platelet concentrates"; During the postoperative period, an average hemotransfusion of 1.34 "globular packages", 0.81 bags of "fresh frozen plasma" and 0.71 bags of "platelet concentrates" were recorded. The details are shown in Table 17. The average hemoglobin value prior to hypogastric artery ligation is $12.85 \mathrm{gr}$, and the average hemoglobin after the surgical event was 7.89gr as shown in the following table The nosocomial stay was reported in days of the patients studied being "hospitalized in gynecology and obstetrics floor" an average of 3.16 days and in UCIA an average of 1.79 days. The details are shown in Tables 18 \& 19.

Table 17: Displays the report of trans and postoperative hemotransfusion in the patients studied. ${ }^{*} D E$ - standard deviation

\begin{tabular}{|c|c|c|c|c|}
\hline \multicolumn{5}{|c|}{ Hemotransfusión Transoperatoria } \\
\hline Amount & MIN & Max & Average & ${ }^{*}$ DE \\
\hline PG & 0 & 7 & 1.13 & 1.78 \\
\hline PFC & 0 & 4 & 0.99 & 0.91 \\
\hline Conc. PLAQ & 0 & 10 & 1.14 & 2.05 \\
\hline \multicolumn{5}{|c|}{ Postoperative Hemotransfusion } \\
\hline PG & 0 & 9 & 1.34 & 2.34 \\
\hline PFC & 0 & 8 & 0.81 & 1.81 \\
\hline Conc. PLAQ & 0 & 10 & 0.71 & 2.23 \\
\hline
\end{tabular}


Table 18: Displays the report of hemoglobin and hematocrit before and after the surgical event. * $D E$ - standard deviation.

\begin{tabular}{|c|c|c|c|c|}
\hline \multicolumn{5}{|c|}{ Preoperative Hemoglobin } \\
\hline Amount & MIN & Max & Average & $*$ DE \\
\hline Hemoglobin & $9.0 \mathrm{GR}$ & $15.5 \mathrm{GR}$ & 12.85 & 1.45 \\
\hline Hematocrit & 21.6 & 46 & 38.5 & 4.59 \\
\hline \multicolumn{5}{|c|}{ Postoperative Hemoglobin } \\
\hline Hemoglobin & $6.22 \mathrm{GR}$ & $15.5 \mathrm{GR}$ & $7.89 \mathrm{GR}$ & 4.47 \\
\hline Hematocrit & 18 & 46 & 23.63 & 13.34 \\
\hline
\end{tabular}

Table 19: Displays the UCIA floor and gynecology hospitalization days report in the patients studied. ${ }^{*} D E$ - standard deviation.

\begin{tabular}{|c|c|c|c|c|}
\hline \multicolumn{5}{|c|}{ Hospitalization } \\
\hline Núm. Days & MIN & Max & Average & ${ }^{*}$ DE \\
\hline Floor & 1 & 12 & 3.16 & 1.87 \\
\hline UCIA & 0 & 15 & 1.79 & 3.05 \\
\hline
\end{tabular}

Of the 38 patients undergoing hypogastric artery ligation, 29 (76.31\%) were recorded patients with single indication for LAH, as well as $9(23.68 \%)$ patients had mixed indications, of which they can be broken down as follows. Of the patients who underwent hypogastric artery ligation, the most common single indication was uterine atonia recorded at 17 (44\%) patients, in this study, the probability of performing hypogastric artery ligation by uterine atonia is Odds $\times \mathbf{0 . 7 8}$. Of the 22 (57.8\%) patients who had obstetric bleeding found 15 (68.18\%) patients who had prior C-section history, so in this study, the probability of obstetric bleeding with prior C-section antecedent is Odds 2.12 (Tables 20 \& 21).

Table 20: Displays unique or mixed indications of patients undergoing $\mathrm{LAH}$ in the patients studied (source: clinical record).

\begin{tabular}{|c|c|c|c|}
\hline \multicolumn{4}{|c|}{ Indications of Hypogastric Artery Ligation } \\
\hline \multicolumn{4}{|c|}{ No. 38} \\
\hline Unique Indication of Lah & Frequency & $\%$ & ODDS \\
\hline Placental Acretism & 17 & 44.74 & 0.78 \\
\hline Placenta Previa & 3 & 7.89 & 0.07 \\
\hline Atonia Uterine & 3 & 7.89 & 0.07 \\
\hline Placenta Low Insertion & 2 & 5.26 & 0.05 \\
\hline Uterine Rupture & 2 & 5.26 & 0.05 \\
\hline Severe Preeclampsia & 1 & 2.63 & 0.02 \\
\hline Lah Electiva X C. Itertiva & 1 & 2.63 & 0.02 \\
\hline Mixed Indication of Lah & Frequency & $\%$ & Odds \\
\hline Placental Acretism + P.Pre & 3 & 7.89 & 0.07 \\
\hline $\begin{array}{l}\text { Placenta Previa Total + } \\
\text { Dppni }\end{array}$ & 2 & 5.26 & 0.05 \\
\hline $\begin{array}{l}\text { C. Iterative + Placenta Pevia } \\
+ \text { Acretismo }\end{array}$ & 2 & 5.26 & 0.05 \\
\hline Atonia Uterine + Acretism & 1 & 2.63 & 0.02 \\
\hline Atonia Uterine + Ehie & 1 & 2.63 & 0.02 \\
\hline Total & 38 & 100 & \\
\hline
\end{tabular}

Table 21: It shows the report of patients who underwent hypogastrica artery ligation by uterine atonia in the patients studied, the probability rate (oddsodds) is 0.78 .

\begin{tabular}{|c|c|c|c|}
\hline \multicolumn{4}{|c|}{ Hypogastrican Artery Ligation } \\
\hline & This & Absent & Total \\
\hline This & 17 & 0 & 17 \\
\hline Absent & 21 & 0 & 21 \\
\hline TOTAL & 38 & 0 & 38 \\
\hline
\end{tabular}

Of the 38 patients in the study, 22 (57.8\%) patients had obstetric bleeding, of these, 18 (47.36\%) were recorded patients who culminated in obstetric hysterectomy, so in this study, the probability of culminating in hysterectomy with obstetric hemorrhage is Odds $\mathbf{4 . 2}$. Of the 38 patients undergoing hypogastric artery ligation (2 for each patient in our study) 1 (2.68\%) patient with post-LAH complication, being in this study, the probability of presenting complications by odds hypogastric artery ligation 0.027 as shown in the following Tables 22-23.

Table 22: It shows the report of patients who had obstetric hemorrhage with prior C-section history, the probability of bleeding probability in this Odds study 2.12 .

\begin{tabular}{|c|c|c|c|c|}
\hline \multirow{2}{*}{} & \multicolumn{4}{|c|}{ Patients with Obstetric Hemorrhage } \\
\cline { 2 - 5 } & & This & Absent & Total \\
\hline \multirow{3}{*}{$\begin{array}{l}\text { Previous } \\
\text { C-section }\end{array}$} & This & 15 & 0 & 15 \\
\cline { 2 - 5 } & Absent & 3 & 4 & 7 \\
\cline { 2 - 5 } & TOTAL & 18 & 4 & 22 \\
\hline
\end{tabular}

Table 23: Displays the number of patients with complications secondary to the Hypogastric Artery Ligation procedure. In this study, the probability of complications from hypogastric artery ligation is Odds - 0.027 (source: clinical record). ${ }^{*} D E$ - standard deviation.

\begin{tabular}{|c|c|c|}
\hline \multicolumn{3}{|c|}{ Complications of Lah } \\
\hline \multicolumn{3}{|c|}{ No. 38} \\
\hline Lesionvascular & Frequency & Percentage \\
\hline I Lig Art Iliaca Ext & 0 & $0.00 \%$ \\
\hline Ii Tear of Art Iliaca Int & 0 & $0.00 \%$ \\
\hline Iii Hipog Vein Tear & 0 & $0.00 \%$ \\
\hline Iv Sacro Venous Plexus Lesion & 0 & $0.00 \%$ \\
\hline No Injury & 38 & $100.00 \%$ \\
\hline Total & 38 & 100 \\
\hline \multicolumn{3}{|l|}{$\begin{array}{l}\text { COMPLICATIONS OF LAH } \\
\text { *DE S } 0.017\end{array}$} \\
\hline Lesion Ureteral & Frequency & Percentage \\
\hline I Acodamiento & 0 & $0 \%$ \\
\hline Ii Wall Injury & 0 & $0 \%$ \\
\hline Iii Ligature & 1 & $2.63 \%$ \\
\hline Iv Total Section & 0 & $0.00 \%$ \\
\hline No Injury & 37 & $97.37 \%$ \\
\hline Total & 38 & 100 \\
\hline
\end{tabular}




\section{Discussion}

Postpartum bleeding remains one of the leading causes of death in underdeveloped countries, even if the resources are available to correct the post-mass blood loss problem. Perhaps one of the main causes of high maternal morbidity is the delay in resorting to surgical techniques, once conservative measures have failed.

Considering that postpartum hemorrhage is the second leading cause of maternal mortality in Mexico reported by SINAIS (National Health Information System), authors such as Reich and Nechtow [25,26]. believe that the hypogastric artery ligation technique is underused in the management of postpartum hemorrhage, probably due to fear of complications that may arise after this procedure. However, the American College of Obstetricians and Gynecologists (ACOG) recommends the ligation of hypogastric arteries as a useful procedure in the treatment of peripartum hemorrhage [27].

This study on hypogastric artery ligation in Obstetrics is not the first to be conducted in Mexico, but it is one of the first to contribute the HGR 36 IMSS San Alejandro Puebla. In our working universe 5562 births were recorded in the HGR 36 IMSS San Alejandro Puebla from June 2012 to December 2012, in which 3032 (54.5\%) was reported births by vaginal delivery and $2530(45.5 \%) \mathrm{C}$-section births. It was in the third decade of life, where the most frequent age was found, being the average age of 26.9 years, discordant to Hurtado Estrada's study (2009), which reports its average population of 37 years [28,29]. In our universe there was a frequency of 38 patients at risk of obstetric bleeding, who underwent ligation of hypogastric arteries, of which $9(7.89 \%)$ patients completed their pregnancy by vaginal delivery and 29 (92.11\%) C-section in the study period covered.

Patient parity was $2.5+/-1.9$ ( 0 to 5 ), the age of termination of pregnancy was on average 37.3 weeks with $D E+/-2.72$ (2442 weeks). Gestational ages similar to those reported by A.Y. Shahin et al. (2010) [30]. The safety of the surgical technique of hypogastric ligation was checked at only 1 (2.63\%) patient with complication after LAH, being in this study, the probability of presenting complications by ligation of hypogastric arteries Odds 0.027, result similar to that presented by Serrano Berrones (2013), who reports $1 \%$ complications in his study [28]. Uterine atonia $(44.74 \%)$ it was the most common indication for the ligation of hypogastric arteries, followed by placental Acretism (7.89\%), as in the study of VM Joshi and cols (2007) in which it was recorded as the main cause of uterine atonia with a frequency of 32.7\% [25].

Of the $22(57.8 \%)$ patients who had obstetric bleeding, 15 of them $(68.18 \%)$ they had a previous C-section antecedent, so in this study, the probability of obstetric bleeding with prior C-section antecedent is Odds 2.12. Successful management of hypogastric artery ligation was recorded at 14 (36.84\%) patients who were not performed obstetric hysterectomy, a result not far from that found in the Debasmita Mandal y cols study (2013) where $50 \%$ of cases prevented obstetric hysterectomy after ligation of hypogastric arteries [27]. Considering the volume of bleeding, we find in our study, an average bleeding of $1485 \mathrm{cc}$, with DE +/$1027 \mathrm{cc}$, similar figures can be observed in the study of Serrano Berrones (2013), who reports transoperative bleeding using the technique of ligation of hypogastric arteries from 500 to $2000 \mathrm{cc}$. with an average of $1000 \mathrm{cc}$ [28].

Of the patients who required hemotransfusion, $63.15 \%$ deserved hemotransfusion, the remaining patients did not. The average transoperative hemotransfusion of globular package was 1.13 unit of globular package, 0.99 unit of fresh frozen plasma and 1.14 unit of platelet concentrates; the average postoperative hemotransfusion of globular package was $1.34 ; 0.81$ unit of fresh frozen plasma and 0.71 unit of platelet concentrates. Compared to other authors such as Hurtado estrada (2009), who records an average of 2 globular packages after ligation of hypogastric arteries in his study [29], higher than in ours.

In relation to the average preoperative haemoglobin was $12.85 \mathrm{gr}$ with DE $1.45 \mathrm{gr}$, the average postoperative of $7.89 \mathrm{gr}$ with DE 4.47gr, as well as the average preoperative hematocrit of 38.53 and the average postoperative of 23.63. The number of days of hospital stay after the hypogastric artery ligation procedure was recorded in hospital floor of 3.16 days $O F+/-1.87$ days, and in UCIA 1.79 days with $D E+/-3.05$. Compared to other studies such as Serrano Berrones (2013), which reports the number of days in regional hospital Mr. Adolfo López Mateos a maximum number of 23 days of hospitalization after the surgical procedure of ligation of hypogastric arteries 28, our figures were lower than those already mentioned.

Registered 1 (2.63\%) with postoperative complication secondary to ligation of hypogastric arteries, distant result to authors such as Abel M and cols. (2009), who report up to $13.3 \%$ complications from post-ligation ureter ligation of hypogastric arteries [31]. Maternal mortality was found absent in our study. However, other authors have recorded mortality rates up to $6.7 \%$ after this procedure. In this research, although it is a descriptive study, with a sample of patients limited by time, it yielded important data in relation to patients with obstetric hemorrhage, such as the fact that there are no perinatal deaths, nor maternal deaths in patients undergoing hypogastric artery ligation, finding only one patient complicated from ureteral injury of all studies; this situation probably reflected the previous training of medical personnel in our hospital, implemented in recent times, but above all that the idea that "obstetric hysterectomy" is no longer the first surgical option for handling obstetric bleeding has changed.

With the analysis of the data obtained, an overview of the behavior of obstetric bleeding and its surgical management in this hospital unit was obtained. Future studies, probably comparative and/or experimental, may take into account the hypogastric 
artery ligation technique as a useful surgical procedure in the management of obstetric bleeding. Probably in order to check, compare and/or corroborate its usefulness to standardize and give better care to the pregnant patient at risk of obstetric bleeding. This is why the surgical technique of ligation of hypogastric arteries was observed as a safe, first-line procedure for the control of obstetric bleeding, so as more experience is gained and better results are achieved, a progressive increase in its application in women with obstetric bleeding will be seen by reducing morbidity and maternal mortality with optimal survival. Not forgetting that the effectiveness of the procedure will depend on its timely performing, adequate indication and good surgical technique.

\section{Conclusion}

Complication after ligation of hypogastric arteries was presented in 1 patient with ureteral ligation. There were no vascular complications. Maternal mortality was $0 \%$. Perinatal mortality was $0 \%$.

\section{References}

1. Priya VR, Deborah AW (2010) Postpartum hemorrage: evidencebased medical interventions for prevetion and treatment. Clin Obstet Gynecol 53(1): 165-181.

2. (2009) Diagnosis and treatment of obstetric bleeding in the second half of pregnancy and postpartum. Mexican Institute of Social Security, Mexico.

3. Shields L, Smalarz K, Reffigee L, Mugg S, Burdumy TJ, et al. (2011) Comprenhensive maternal hemorrhage protocols improve patient safety and reduce utilization of blood products. Am J Obstet Gynecol 205(4): 368.e1-8.

4. Rojas, J, Miranda J, Ramos E, Fernández J (2011) Critical care in obstetric patient. Complicaciones Complications, interventions and mother-of-profile outcomes. Clin Invest Gin Obst 38(2): 44-49.

5. American College of Obstetricians and Gynecologists (2006) ACOG Practice Bulletin: Clinical Management Guidelines for ObstetricianGynecologists Number 76, postpartum hemorrhage. Obstet Gynecol 108(4): 1039-1047.

6. Reyes OA (2011) Carbetocin vs. Oxytocin for the prevention of postpartum bleeding in large patients multiparas: randomized controlled study. Clin Invest Gin Obst 38(1): 2-7.

7. Callaghan WM, Kuklina EV, Berg CJ (2010) Trends in postpartum hemorrhage: United States, 1994 -2006. Am J Obstet Gynecol 202(4): 353.e1-6.

8. Priya VR, Deborah AW (2010) Postpartum Hemorrhage: Evidencebased Medical Interventions for prevention and treatment. Clin Obstet Gynecol 53(1): 165-181.

9. Grotegut CA, Paglia MJ, Johnson LNC, Thames B, James AH, et al. (2011) Oxytocin exposure during labor among women with postpartum hemorrhage secondary to uterine atony. Am J Obstet Gynecol 204(1): 56.e1-6.
10. Fuller AJ, Bucklin B (2007) Obstetrics hemotherapy. bstet Gynecol Clin N Am 34(3): 443-458.

11. Parker WH, Wagner WH (2010) Gynecologic Surgery and the Management of Hemorrhage. obstet Gynecol Clin n am 37(3): 427-436.

12. Malvino E, Eisele G, Martínez M (2009) Exanguinent obstetric hemorrhages Hemorragias. Clin invest Gin Obst 36 (1): 2-8.

13. Pacheco (2011) Medical management of obstetric hemorrhage. Am J Obstet Gynecol.

14. Briones Garduño JC, Díaz de León Ponce M, Gutiérrez Vázquez MC, et al. (2010) Paradigms in maternal death. Critical medicine and intensive care 114(4): 185-189.

15. https://salud.edomex.gob.mx/cevece/home.html

16. http://www.milenio.com/cdb/doc/impreso/9003526

17. Fernández Cantón SB, Gutiérrez Trujillo G, Viguri Uribez R (2012) Maternal mortality and abortion in Mexico. Bol Med Hosp Infant Mex 69(1): 77-80.

18. http://www.scielo.org.mx/pdf/bmim/v69n1/v69n1a11.pdf

19. www.generoysaludreproductiva.salud.gob.mx

20. (2011) Research protocol: Care of GYN patients, in the intensive care unit of IMSS Regional General Hospital No. 36 in the period from 16 March 2011 to 31 July 2011.

21. (2011) surgical training in hypogastric artery ligation. State Department of Reproductive Health populates.

22. (2009) Clinical Practice Guides Treatment and Transfusional Support in Women with Obstetric Hemorragia. Ginecol Obstet Mex 77(4): S87-S128.

23. Oyelese Y, Scorza WE, Mastrolia R, Smulian JC (2007) Postpartum hemorrhage. Obstet Gynecol N Am 34(3): 421-441.

24. Urquiza-Nunez, Rosa Maria, Weed-Canseco, Lorraine, MoralesCarmona E, et al. (2010) The challenges to avoid maternal mortality in Mexico. Live health 2(6): 28-32.

25. Oshi V, Otiv S, Majumder R, Nikam Y, Shrivastava M, et al. (2007) Internal iliac artery ligation for arresting postpartum haemorrhage. BJOG 114(3): 356-361.

26. http://sinais.salud.gob.mx/muertesmaternas/

27. Mandal D, Kumar T (2013) Role of hypogastric artery ligation in pelvic haemorrhage is still alive. Al Ameen J Med Sc i 6(1): 12-16.

28. Serrano Berrones MA (2013) Comparison of two conservative surgical techniques for the treatment of obstetric bleeding. Rev Esp Méd Quir 18:100-107.

29. Hurtado Estrada G, Cardenas Gonzalez S (2009) Ligature of hypogastric arteries, a heroic surgery to prevent mortality in gynecology. Maternal children's research archives I(3): 138-143.

30. Shahin AY (2010) Bilateral uterine artery ligation plus B-lynch procedure por atonic postpartum hemorrhage with placenta acreta. International journal of gynecology and obstetrics 108: 187-190.

31. Abdel-Naby (2009) Prophylactic internal iliac artery ligation in cases of postpartum hemorrhage due to rupture uterus (randomized controlled study). Bull Alex Fac Med 45(1). 
(C) This work is licensed under Creative Commons Attribution 4.0 License DOI: 10.19080/JGWH.2020.20.556031

\section{Your next submission with Juniper Publishers} will reach you the below assets

- Quality Editorial service

- Swift Peer Review

- Reprints availability

- E-prints Service

- Manuscript Podcast for convenient understanding

- Global attainment for your research

- Manuscript accessibility in different formats

( Pdf, E-pub, Full Tsext, Audio)

- Unceasing customer service

Track the below URL for one-step submission

https://juniperpublishers.com/online-submission.php 